\title{
Involving Undergraduates in Publishable International Research: Experiences in Latin America
}

\author{
Brien K. Ashdown* \\ Department of Psychology, Hobart and William Smith Colleges, Geneva, NY, United States
}

Keywords: Latin America, undergraduate research, international research, guatemala, cultural psychology

Involving undergraduates in research is important to many sciences such as biology, chemistry, physics, and psychology (Russell et al., 2007; Thiry and Laursen, 2011). Cultural psychological research often occurs in "the field," far from home. This scholarship has specific challenges that can make it difficult to involve undergraduates. These challenges, however, are worth the rewards of introducing them to international and culturally-based research. Here, I provide suggestions from my experiences guiding 26 undergraduates while conducting psychological research in Guatemala. This work has resulted in five publications (including nine undergraduate co-authors), various conference presentations, and other ongoing projects with another seven student collaborators (García Egan et al., 2014; Faherty et al., 2016; Ashdown and Buck, 2018; Ashdown et al., 2018; Rohner et al., 2019).

Many challenges of conducting research with undergraduates while abroad are similar

OPEN ACCESS

Edited by:

Traci Giuliano,

Southwestern University,

United States

Reviewed by:

Stuart McKelvie,

Bishop's University, Canada

Melissa Burns-Cusato,

Centre College, United States

*Correspondence:

Brien K. Ashdown

ashdown@hws.edu

Specialty section:

This article was submitted to

Educational Psychology,

a section of the journal

Frontiers in Psychology

Received: 28 November 2018

Accepted: 08 March 2019

Published: 29 March 2019

Citation:

Ashdown BK (2019) Involving

Undergraduates in Publishable

International Research: Experiences in

Latin America. Front. Psychol. 10:656.

doi: 10.3389/fpsyg.2019.00656 to working with undergraduates on campus. Undergraduates are research novices, requiring significant supervision and training (Shellito et al., 2001; Thiry and Laursen, 2011). Challenges specific to international research, like working in unfamiliar locations and avoiding specific cultural and ethical pitfalls, can be managed by focusing on five issues: (1) establish local collaborations, (2) avoid "safari" research, (3) understand students' cultural and research skills, (4) get official institutional support for students' travel and work, and (5) model international research ethics.

\section{ESTABLISH LOCAL COLLABORATIONS}

International research requires partnerships with local collaborators (Pao, 1992; Ashdown and Buck, 2018). Such collaborations are more successful (Pao, 1992), and local collaborators have better access to local populations, understand local customs, and can serve as cultural ambassadors in addition to collaborators. It is important to model these collaborations for undergraduates to teach them the value of such collaborators. Working with local collaborators can also lead to the opportunity to include local undergraduates as collaborators, a worthy goal of any international psychologist. For example, I worked with two Guatemalan students on a project exploring Guatemalan mothers' parenting beliefs (García Egan et al., 2014). I was introduced to these student collaborators through my previous collaborations with other local Guatemalan scholars.

Working with local collaborators helps researchers avoid falling into the trap of the "White savior complex" (Straubhaar, 2014; Belcher, 2016; Bex and Craps, 2016; Jailani, 2016; Ashdown and Buck, 2018). This complex occurs when researchers (usually highly-educated, relatively wealthy White people from the Global North) view themselves (and are sometimes viewed by participants) as having all necessary skills and knowledge to research an issue or solve a problem. With deep roots in colonialism (Rigney, 1999; Rios, 2015; Aronson, 2017; Ashdown and Buck, 2018), this behavior should be avoided at all costs. Conducting research in partnership with local collaborators ensures investigators avoid culturally imperialistic research practices (Dupre, 1994; Wilmshurst, 1997), while teaching undergraduates this important practice. 


\section{AVOID "SAFARI” RESEARCH}

The term "safari research" describes scholarship by researchers who lack deep understandings of the cultures they study. This practice is unethical, promotes the White savior complex, and should never be modeled for undergraduates. Otherwise, scholars may reify the structures of colonialism in their work and perpetuate it in a new generation of researchers. Instead, researchers should limit themselves to working in cultural contexts where they have experience, and where they can receive support from, and in turn support, local collaborators. This issue is closely tied the White savior complex, and of such importance that I recently published a critique of the way cultural psychologists interact with foreign cultures (Ashdown and Buck, 2018). This publication has an undergraduate author and is based on her honors thesis-a good example of how students can do good scholarship about cultural psychology as well as within cultural psychology.

Safari research intensifies the complexities of working in a foreign language. I believe researchers should not work in a language they cannot speak. Even when fluent in a second language, they should work with local collaborators who are native speakers. Translations of measures and surveys should always utilize rigorous back-translation processes that involve native speakers of the language-regardless of how well a researcher might speak both languages (Brislin, 1970; Dorcas et al., 2000; Hambleton and Zenisky, 2011).

Language is an area where undergraduate students can be of great help. In past projects, I involved undergraduates who were native Spanish speakers (often bilingual in Spanish and English) to help with the translation process. While translation work alone does not meet the requirements for authorship, it is valuable and always recognized in the authors' note of publications and presentations (Ashdown et al., 2017). Often, this effort serves as the first step, or "try out" aspect, of getting a new undergraduate researcher involved in my scholarship.

Related to the complexities of language is an awareness of local cultural norms (Rigney, 1999; Rogler, 1999; Finnemore, 2009). It is impossible for safari researchers to practice ethical scholarship in a culture where they do not understand customs surrounding concepts like gender relations or social hierarchies. When I take undergraduates abroad, I require a significant amount of reading and meetings before departure. These are not replacements for the years of immersion necessary for cultural proficiency (Ruben, 1989), but serve to prepare undergraduates for international field work. For example, students who work with me read The Guatemalan Reader (Grandin et al., 2011) before our trip and meet with me 2-3 times a month to discuss their reading.

Finally, for students (or other researchers) hoping to begin a research program in a culture with which they are currently unfamiliar there are some tactics that will help them avoid the pitfalls of safari research. Begin establishing relationships with potential local collaborators before traveling (e.g., via email listservs and Internet groups), and try to build bridges with other international researchers working in the same area with an eye toward future collaborations and a "foot in the door" to learn about the culture. And, in the end, it is better to take someone with you who is familiar with the culture (or hire a translator to accompany you) than it is to become a safari researcher.

\section{UNDERSTAND AND SUPPORT STUDENTS' CURRENT SKILLS}

Many undergraduates have international experience, and may have studied abroad in cultures similar to the one where you work. They come with valuable cultural skills and understanding - though their experience maybe more superficial than you would like. It is important to talk with these students to determine the intercultural skills they have developed from their experiences and what others need cultivating.

Students without international experience can still be valuable research assistants. They do not need to travel to conduct research, nor do they need previous international experiences to be important assets in international scholarship. Students who do not travel to collect data can be members of a research team assigned other tasks. On my team, these students aid in data analysis, literature searches, and writing. In all of my publications based on data from Guatemala that have undergraduate coauthors, some of those authors did not travel with me, but did significant work on writing once I returned to campus with data. I still require them to have a solid grounding in Guatemalan culture-just as students who travel with me are required to complete certain readings and meet to discuss cultural and current events, so are students who do not.

Keep in mind that whether or not students have relevant cultural experience, it does not compensate for a lack of research skills. Undergraduates conducting international research need support and training in basic skills related to the project. These skills often include interviewing, managing focus groups, or navigating local research customs. The line between cultural skills and research skills can blur-a student with great interviewing skills still needs to understand local norms around social interactions and speak the language in which the interviews occur. Working with undergraduates in international contexts requires that you balance the need for these skills with providing the students the experiences needed to gain and develop the skills.

\section{OBTAIN INSTITUTIONAL SUPPORT}

Institutional support is important for any scholarship involving undergraduates; this support is particularly important for international research, as travel costs can exceed what many researchers can pay, and there can be higher liability connected to travel. Because of the costs of traveling, my institution has a few competitive scholarships to support students' international work. Official institutional support may also make it easier for students to apply for external funding.

Keep in mind that while having institutional support makes the process of traveling with students to conduct research more feasible for various reasons, it may not be necessary (you should check institutional policies). I have traveled with students both as part of an official program with my institution and as individual students (or small groups of students) accompanying me during 
summer break. The comfort you have traveling without official institutional support should have the largest influence on how you make this decision.

One aspect of this decision might be whether the institution will provide liability protection for you, which is something I always consider when I take students to Guatemala. I have yet to experience personal risk while traveling with students, but I take steps to protect myself. For example, I edited a copy of the legal liability paperwork students complete, sign, and notarize before they travel on an official institutional program (e.g., study abroad) so that it acts as a contract between me and the students. It serves the purpose of protecting me from liability in many situations. I also suggest having a discussion with your insurance agent about possible insurance coverage.

\section{MODEL GOOD INTERNATIONAL RESEARCH ETHICS}

My last suggestion, to model good research ethics, may seem like a suggestion that all researchers should follow. I believe this modeling deserves special consideration when conducting international research. As mentioned previously, these ethics include avoiding a "White savior complex," getting nowhere near cultural or scientific colonialism, and not engaging in safari research. It also includes a few methodological ethics specific to international research.

First, we should always get Institutional Review Board (IRB) approval for any research that involves human participants (or an Institutional Animal Care and Use Committee for nonhuman participants), which clearly is not specific to international research (Amdur and Biddle, 1997; Oakes, 2002). This, however, is not enough. We should ensure that we get approval from a local IRB, too (Greene and Geiger, 2006; Ravina et al., 2009). If there is not an appropriate and relevant local IRB, we should get ethics approval from an authorized and appropriate person in the community or organization where we are working, such as a village elder, elected official, or program director.

Second, in addition to working with local collaborators, we should ensure that collaborators receive appropriate authorship recognition. No matter where our collaborators live and work, if their effort on our project would constitute authorship recognition on a publication or presentation for a USA-based colleague, our international collaborators are entitled to that same recognition. Not including collaborators as authors simply because they do not work in a traditional research setting such as university (e.g., community organizers, program directors, etc.)) is inappropriate. Simply put, all contributions to a project should be ethically and appropriately recognized.

\section{REFERENCES}

Amdur, R. J., and Biddle, C. (1997). Institutional review board approval and publication of human research results. JAMA 277, 909-914. doi: 10.1001/jama.1997.03540350059034

Aronson, B. A. (2017). The white savior industrial complex: a cultural studies analysis of a teacher educator, savior film, and future teachers. J. Crit. Thought Prax. 6, 36-54. doi: 10.31274/jctp-180810-83
Third, and related to the second point, I have made a conscious decision to publish my Guatemala-based work in journals that are accessible to local Guatemalan scholars. This decision often means publishing in open-access journals because many Guatemalan scholars cannot afford the excessive cost of accessing databases and journals. Because many highlyranked open-access journals have hefty publication fees (which my institution will not pay), I often choose to publish in good journals that are not at the top of the journal ranks. Otherwise, I would find it difficult to ethically justify my research because it would not be accessible to my collaborators, their institutions, or other local scholars (Kansa et al., 2013; Butler, 2016; Schiltz, 2018). For example, I have published with student collaborators in the Revista Interamericana de Psicología (García Egan et al., 2014), the Psi Chi Journal of Psychological Research (Faherty et al., 2016), and the Acta de Investigación Psicológica (with a recently graduated local collaborator; Gomez and Ashdown, 2013).

\section{CONCLUSION}

Involving undergraduates in high-quality international research is one of the aspects of my career I most enjoy. As a cultural psychologist, my research occurs in the context of the beautiful, colorful, and exciting culture and geography of Guatemala. While working with students is a highlight of my work, it can be challenging to involve undergraduates in this type of research process. I have found, though, that challenges pale in comparison to the rewards that come from introducing my undergraduates to the process of international and culturally-based research, and to the splendor of Guatemala.

\section{AUTHOR CONTRIBUTIONS}

The author confirms being the sole contributor of this work and has approved it for publication.

\section{FUNDING}

Partial funding was provided by the Department of Psychology at Hobart and William Smith Colleges.

\section{ACKNOWLEDGMENTS}

This manuscript was improved through the feedback kindly provided by Sara E. Branch, Carrie M. Brown, and Narnia Brockman.

Ashdown, B. K., and Buck, M. (2018). International aid as modern imperialism: what does cross-cultural psychology really have to offer? J. Cross Cult. Psychol. 49, 545-553. doi: 10.1177/00220221187 68428

Ashdown, B. K., Faherty, A. N., Brown, C. M., Hanno, O., Belden, A., and Weeks, P. B. (2018). Fathers and perceptions of God play an important role in psychological adjustment among emerging adults in Guatemala and the United States. J. Genet. Psychol. 9, 1-16. doi: 10.1080/00221325.2018.1502148 
Ashdown, B. K., Gibbons, J. L., de Baessa, Y., and Brown, C. M. (2017). Using adolescents' drawings to reveal stereotypes about ethnic groups in Guatemala. Am. J. Orthopsychiatry 87, 626-635. doi: 10.1037/ort00 00277

Belcher, C. (2016). There is no such thing as a post-racial prison: neoliberal multiculturalism and the white savior complex on orange is the new black. Televis. New Med. 17, 491-503. doi: 10.1177/152747641667498

Bex, S., and Craps, S. (2016). Humanitarianism, testimony, and the white savior industrial complex: what is the what versus kony 2012. Cult. Critiq. 92, 32-56. doi: $10.5749 /$ culturalcritique.92.2016.0032

Brislin, R. W. (1970). Back-translation for cross-cultural research. J. Cross Cult. Psychol. 1, 185-216. doi: 10.1177/135910457000100301

Butler, D. (2016). Dutch Lead European Push to Flip Journals to Open Access: Academic consortia urge Faster Changes in Scholarly Publishing. Nature News. Retrieved from https://www.nature.com/news/dutch-lead-european-push-toflip-journals-to-open-access-1.19111

Dorcas, B., Bombadier, C., Guillemin, F., and Ferraz, M. B. (2000). Guidelines for the process of cross-cultural adaptation of self-report measures. Spine 25, 3186-3191. doi: 10.1097/00007632-200012150-00014

Dupre, J. (1994). Against scientific imperialism. PSA 2, 374-381. doi: 10.1086/psaprocbienmeetp.1994.2.192948

Faherty, A. N., Eagan, A., Ashdown, B. K., Brown, C. M., and Hanno, O. (2016). Examining the reliability and convergent validity of IPARtheory measures and their relation to ethni attitudes in Guatemala. Psi Chi J. Psychol. Res. 21, 276-288. doi: 10.24839/b21.4.276

Finnemore, M. (2009). Norms, culture, and world politics: insights from Sociology's institutionalism. Int. Organ. 50, 325-347. doi: $10.1017 /$ S0020818300028587

García Egan, P., Batz, R., Pauley, D., Gibbons, J. L., and Ashdown, B. K. (2014). Niños buenos vs niños malos: etnoteorías de un grupo de madres Guatemaltecas [Good children vs bad children: ethnotheories of a group of guatemalan mothers]. Rev. Interam. Psicol. 48, 183-193.

Gomez, R., and Ashdown, B. K. (2013). Efectividad de tratamiento EMDR en personas Guatemaltecas con síntomas de trauma psicológica [Effectiveness of EMDR treatment for Guatemalans with symptoms of psychological trauma]. Acta Investig. Psicol. 3, 1264-1270. doi: 10.1016/S2007-4719(13)70965-7

Grandin, G., Levenson, D. T., and Oglesby, E. (2011). The Guatemala Reader: History Culture Politics. Durham, NC: Duke University Press.

Greene, S. M., and Geiger, A. M. (2006). A review finds that multicenter studies face substantial challenges but strategies exist to achieve institutional review board approval. J. Clin. Epidemiol. 59, 784-790. doi: 10.1016/j.jclinepi.2005. 11.018

Hambleton, R. K., and Zenisky, A. L. (2011). "Translating and adapting tests for cross-cultural assessments," in Cross-Cultural Research Methods in Psychology, eds D. Matsumoto and F. J. R. van de Vijver (Cambridge: Cambridge University Press), 46-74.

Jailani, Y. (2016). The struggle of the veiled woman: 'White Savior Complex' and rising Islamophobia create a two-fold plight. Harvard Int. Rev. 37, 51-54.

Kansa, E. C., Kansa, S. W., and Goldstein, L. (2013). On ethics, sustainability, and open access in archeology. SAA Archeol. Rec. 13, 15-22.
Oakes, J. M. (2002). Risks and wrongs in social science research: an evaluator's guide to the IRB. Eval. Rev. 26, 443-479. doi: 10.1177/019384102236520

Pao, M. L. (1992). Global and local collaborators: a study of scientific collaboration. Inform. Process. Manage. 28, 99-109.

Ravina, B., Deuel, L., Sidrowf, A., and Dorsey, E. R. (2009). Local institutional review board (IRB) review of a multicenter trial: local costs without local context. Ann. Neurol. 67, 258-260. doi: 10.1002/ana.21831

Rigney, L.-I. (1999). Internationalization of an Indigenous anticolonial cultural critique of research methodologies: a guide to Indigenist research methodology and its principles. Wicazo Sa Rev. 14, 109-121. doi: 10.2307/1409555

Rios, V. M. (2015). Decolonizing the white space in urban ethnography. City Commun. 14, 258-261. doi: 10.1111/cico.12122

Rogler, L. H. (1999). Methodological sources of cultural insensitivity in mental health research. Am. Psychol. 54, 424-433. doi: 10.1037/0003-066X.54.6.424

Rohner, R. P., Ania, F., Melendez-Rhodes, T., Kuyumcu, B., Machado, F., Roszak, J., et al. (2019). Psychological maladjustment mediates the relation between rememberances of parental rejection in childhood and adults' fear of intimacy: a multicultural study. Cross Cult. Res. doi: 10.1177/1069397118822992. [Epub ahead of print].

Ruben, B. D. (1989). The study of cross-cultural competence: traditions and contemporary issues. Int. J. Intercult. Relat. 13, 229-240. doi: 10.1016/0147-1767(89)90011-4

Russell, S. H., Hancock, M. P., and McCullough, J. (2007). Benefits of undergraduate research experiences. Science 316, 548-549. doi: $10.1126 /$ science. 1140384

Schiltz, M. (2018). Science without publication paywalls: cOAlition S for the realization of full and immediate open access. PLoS Med. 1:e1002663. doi: 10.1371/journal.pmed.1002663

Shellito, C., Shea, K., Weissman, G., Mueller-Solger, A., and Davis, W. (2001). Successful mentoring of undergraduate researchers. J. Coll. Sci. Teach. 30, 460-464.

Straubhaar, R. (2014). The stark reality of the 'White Saviour' complex and the need for critical consciousness: a document analysis of the early journals of a Freirean educator. Compare 45, 381-400. doi: 10.1080/03057925.2013.876306

Thiry, H., and Laursen, S. L. (2011). The role of student-advisor interactions in apprenticing undergraduate researchers into a scientific community of practice. J. Sci. Educ. Technol. 20, 771-784. doi: 10.1007/s10956-0109271-2

Wilmshurst, P. (1997). Scientific imperialism. BMJ 314, 840-841.

Conflict of Interest Statement: The author declares that the research was conducted in the absence of any commercial or financial relationships that could be construed as a potential conflict of interest.

Copyright (c) 2019 Ashdown. This is an open-access article distributed under the terms of the Creative Commons Attribution License (CC BY). The use, distribution or reproduction in other forums is permitted, provided the original author(s) and the copyright owner(s) are credited and that the original publication in this journal is cited, in accordance with accepted academic practice. No use, distribution or reproduction is permitted which does not comply with these terms. 